\title{
Chapter 20 \\ Current Status and Issues for Urban (Regional Area) Formulation of the Location Normalization Plan: The Case of Niigata City
}

\section{Yoko Ogushi}

\begin{abstract}
In the case that the amount of investment differs between the designated area and other area, the impact on land prices will be unavoidable. In Niigata City, the plan has just been completed. From now on, we need to pay close attention to how to make land use more appropriate by policy guidance and how it affects the land price.
\end{abstract}

Keywords Niigata city - Location normalization plan · Trend in the price of land . Transportation mode $\cdot$ Advisory board

\subsection{Introduction}

The twin prospects of a declining population and a super-elderly society that face Japan have already become a serious issue in regional cities (Ministry of Internal Affairs and Communications 2005), and a faster response is required. In Niigata City, despite a population increase of more than 600 dues to social movements, there has been a more-than-2000 decline in population because of natural movements, which have caused a sharp decline in the net population (FY2013 Niigata Prefecture Population Movement Survey). The population is anticipated to continue declining with natural movement seen as the primary cause. Hence, it is actually quite complicated to consider whether there has been a large decline in the price of land in Niigata City. Observing the changes in the price of land from the published land prices released in March 2017, one can tell that the price of land within the city fell in terms of the average for all land uses but that the rate of decline was $0.4 \%$, a contraction of 0.4 points from the previous year. Even when considered by site,

Y. Ogushi $(\bowtie)$

Niigata University, Niigata, Japan

e-mail: ogushi@sugiyama-u.ac.jp

Y. Asami et al. (eds.), Frontiers of Real Estate Science in Japan, New Frontiers in 
the number of locations in which prices rose increased from 15 to 32, while the yearon-year price change was flat in 36 locations. The price of land only rose in the city center, and land prices rose in areas with easy access to the city center. However, even in Chuo-ku (the central ward), the decline in price was exacerbated in areas that were inconvenient for access to the center.

In the future, it is only natural that there will emerge a difference in the state of readiness between the urban function and residential environments, depending on the guidance zone. (Ministry of Land, Infrastructure and Transport 2014) There will be concentrated development in the businesses of promoting urban renewal and maintenance planning in the urban guidance of the urban facilities/functions zone and residential guidance zones in accordance with the Location Normalization Plan enacted in March 2017. Consequently, this will also likely have an impact on the demand for land and the price of land. Nevertheless, it is not clear as to how much discussion there was with regard to the impact that the plan would have on the trend for change in the price of land when the plan was being formulated.

The author had a valuable opportunity as a committee member on the "Advisory Board to Create a Sustainable City," which formulated this plan. The Advisory Board discussed the matter following an overview of the current state of Niigata City, referring to issues that had aroused the interest of committee members, and talked about the contributions and limits of this plan.

\subsection{Niigata City}

\subsubsection{Current State of Land Use}

Through consolidation during the Heisei era (1989-2019), Niigata City was reorganized as 14 municipalities and 1 city in April 2007, home to a population in excess of 800,000 and spread over an expanded area of $726 \mathrm{~km}^{2}$ (according to the residents' basic ledger population on the Niigata City website). While being a legally designated city, the area under cultivation is 286 million hectares by municipality, which is the largest in the nation. This is substantially larger than Daisen City in Akita Prefecture, which has the nation's second largest area under cultivation, covering 185 million hectares (according to the FY2012 Area of Cultivated Land Survey). Total land use figures point to urban use accounting for approximately $30 \%$ and natural land use accounting for approximately $70 \%$ (Niigata City, page 13), with approximately 560 hectares of underutilized land within the inner-city zone (Niigata City, page 20). In contrast to the areas that are not being used in the inner-city zone, there are large stores and roadside service facilities concentrated along major roads and in suburban areas. 


\subsubsection{Specific Urban Planning}

The "Basic Plan for Urban Planning in Niigata City (Niigata City Urban Planning Master Plan)" was released in Niigata City in July 2007 as though anticipating the idea of the "Ministry of Land, Infrastructure, Transport and Tourism's Grand Design of National Spatial Development Towards 2050," which was released in July 2014. This master plan was aimed at an ideal city, one that was defined as "multiple centers surrounded by fields — creating a compact city with a Niigata feel." The composition of multiple centers is the eight wards derived from the transition to a governmentdesignated city (The transition of Niigata City to a government-designated city occurred on April 1, 2007.). While Niigata City also has a wide area of cultivated land and is reputed to be one of the country's largest grain-producing regions, it comprises a city center and eight wards, each of which is connected by a public transport network and key roads in a skeletal structure that is ideal for a city (see Fig. 20.1).

\subsubsection{Transportation Methods of Niigata City Residents}

If one asks whether public transportation is already complete, the answer is that the current state is vague. Niigata City rearranged its public transportation system to link the central areas of each district, as in the case of the location of ward offices in each district such that each ward has places that are necessary for everyday life (Niigata City 2017). Nevertheless, there were large biases in the manner in which people moved between wards (Fig. 20.2), with $70 \%$ of the residents of Niigata City using cars as the method of transportation, which is overwhelmingly high when compared with other transportation modes. (As above, page 34).

Visualizing the volume of transportation among wards by transportation mode highlights the obviously high degree of dependence on cars (Fig. 20.3). The number of bus users has fallen to about one-third during the past 20 years, from 69 million in

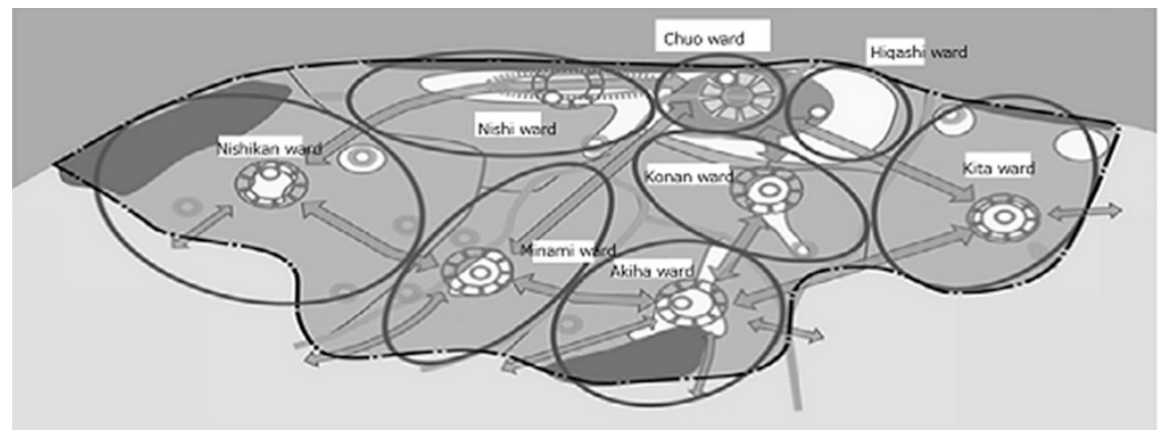

Fig. 20.1 Concept diagram for Niigata City's urban structure: 8 core wards 


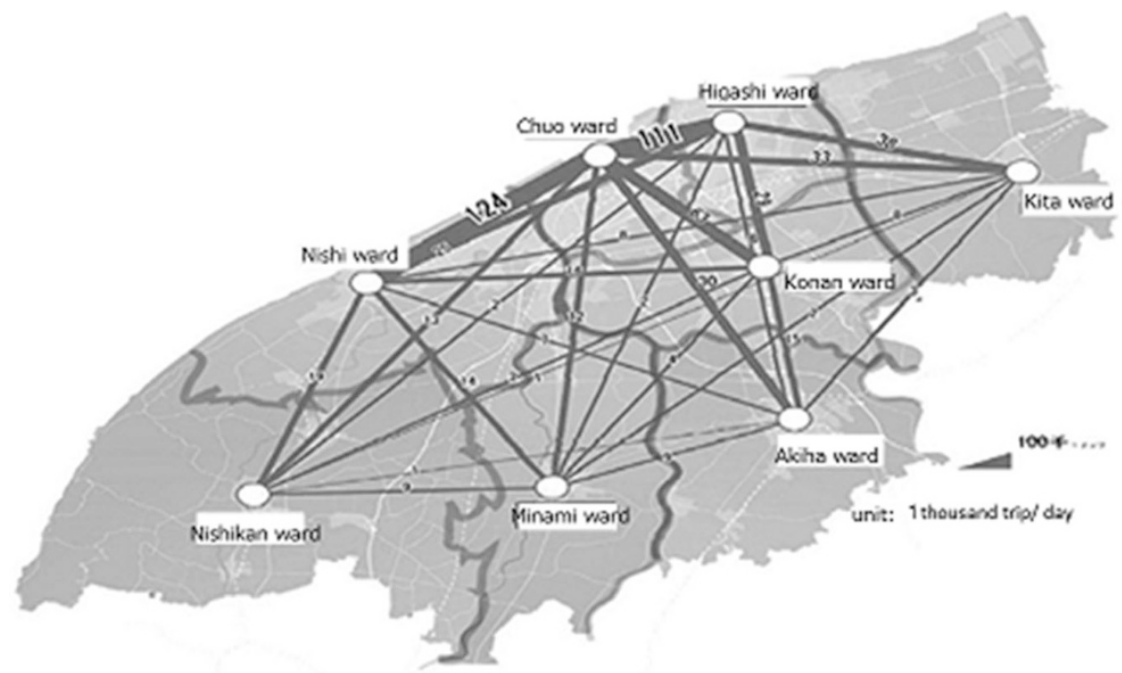

Fig. 20.2 Movement of people between eight core wards. Materials: FY2011 Survey of Urban Transportation Features within Niigata City

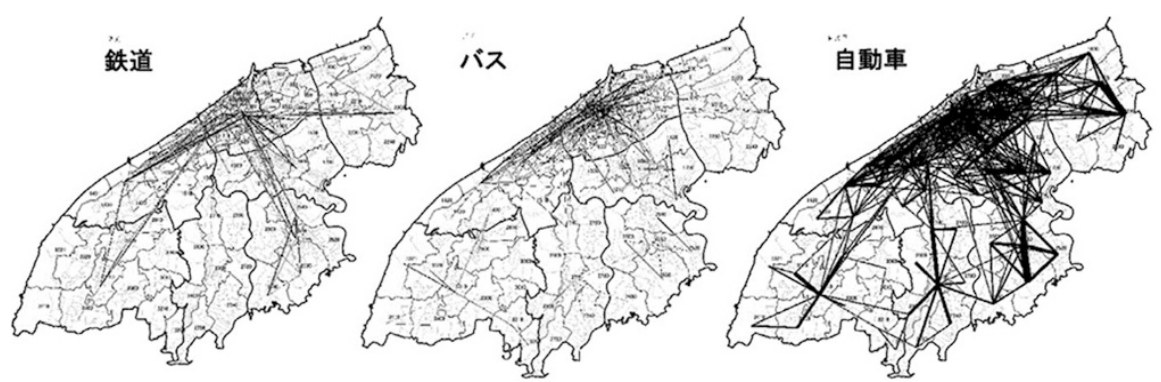

Fig. 20.3 Movement of people between wards (movement between zones by transportation mode). Materials: FY2011 Survey of Urban Transportation Features within Niigata City

1990 to 24 million in 2010. As the number of routes has also fallen with the decline in the number of users, the convenience factor has only declined.

Hence, Niigata City introduced Bus Rapid Transit (BRT) in 2015 with buses running along the main roads as a public-private partnership in an effort to increase access by allocating spare drivers and buses to areas that were inconvenient for transportation.

This is a big step toward dealing with the anticipated increase in demand for public transportation, given the aging population. 


\subsection{Discussion at the Advisory Board to Create a Sustainable City}

\subsubsection{Request for Thorough Explanation on Guidance Zones}

Participants also seriously understood the significance of setting guidance zones to realize appropriate locations. The city explained on numerous occasions: "Appropriate land use will be realized gradually and not through coercion."

This is because there are areas that are not included in residential guidance zones even in the existing inner city, and many people have voiced their concerns. In particular, with regard to the "town area," which is the center of each ward, the plan is to set up such zones as necessary, with one eye on future trends; thus, some ambiguity has been left in. The interest of the board members was also drawn toward the many requests for thorough explanations on the plans themselves as opposed to discussions on detailed settings for an area and the impact. Consequently, the Advisory Board increased the number of meetings it held from the original 3 to 5. There were thorough explanations and discussions, and the Advisory Board put forth many constructive opinions. Nevertheless, although there were many opinions concerning the improvements in efficiency through the implementation of the plan, there was virtually no discussion regarding how concentrated investment in an identified area would impact land price.

\subsubsection{Obviously a Demand for Greater Improvement in Public Transport}

One requirement for compact + network is obviously public transportation. We heard many people advocating the need for diverse public transportation modes because of the large size of the city, the need to access public facilities, everyday shopping in each location, and the concentration of medical facilities in the central area. The population will decline unless there is comprehensive public transportation in this aging society; hence, land prices will fall further, and relocating to the central area will also become inconvenient. The head of the Echizenhama Neighborhood Association also proposed to the Advisory Board members that the number of migrants be increased to create an independent area and acknowledged that the migration of middle-aged and elderly people was obviously one factor in determining enhanced public transportation. 


\subsection{3 “History" of Blockages Before the Merger}

As noted above, Niigata City merged 14 municipalities to create the designated city. Ten years down the line, a growing sense of unity as a city is emerging. However, in firming up the zone to become an area for concentration, there are inevitably policy discussions that assume bias in the allocation of funds, with a tendency for strong opinions to be asserted that "independence needs to be considered because the circumstances differ for each ward." Therefore, it has been virtually impossible to discuss a strategic increase in the price of land in identified areas that would lead to overall optimization of land use.

\subsection{Conclusion}

The Location Normalization Plan in Moroyama, Saitama Prefecture, included a target of increasing the published land prices by at least $10 \%$ in 20 years. This town also forecast that the population would decline by approximately $18 \%$ over the same period (Motoyama Town 2017); however, Moroyama had the strategy of maintaining population density and convenience by guiding residents to live in residential zones, with the promotion of public investment in the guidance zones leading to an increase in the price of land (Moroyama Town 2017).

There is no mention of aspects such as published land prices in Niigata City's plan, and if there were a mistake in the amount of investment in the designated zone and areas outside that zone, the impact on the price of land would no doubt be unaffected. The Advisory Board ended up focusing discussion on improving the current status, and it was unfortunate that advanced discussion with land price awareness was not possible. Still, it is worth noting that the Location Normalization Plan is merely a plan. In the future, how to specifically aim for the appropriate use of land through policy guidance and the impact that this would have on the price of land should be the focus.

Acknowledgments The basis of the figures used in this paper was provided by the Urban Planning Section of Niigata City. I hereby express my deep gratitude for their assistance.

\section{References}

Moroyama Town (2017) Moroyama-Cho Ricchi Tekiseika Keikaku (Moroyama Town urban facility location plan)

Ministry of Land, Infrastructure and Transport (2014) Kokudo no gurando Dezain 2050 Tairyu Sokushingata Kokudo no Keisei (National Ground Design 2050-Formation of ConvectionPromoting National Land)

Ministry of Internal Affairs and Communications (2005) National Census

Niigata City (2017) Ricchi Tekiseika Keikaku (The urban facility location plan) 
Open Access This chapter is licensed under the terms of the Creative Commons Attribution 4.0 International License (http://creativecommons.org/licenses/by/4.0/), which permits use, sharing, adaptation, distribution and reproduction in any medium or format, as long as you give appropriate credit to the original author(s) and the source, provide a link to the Creative Commons licence and indicate if changes were made.

The images or other third party material in this chapter are included in the chapter's Creative Commons licence, unless indicated otherwise in a credit line to the material. If material is not included in the chapter's Creative Commons licence and your intended use is not permitted by statutory regulation or exceeds the permitted use, you will need to obtain permission directly from the copyright holder. 